
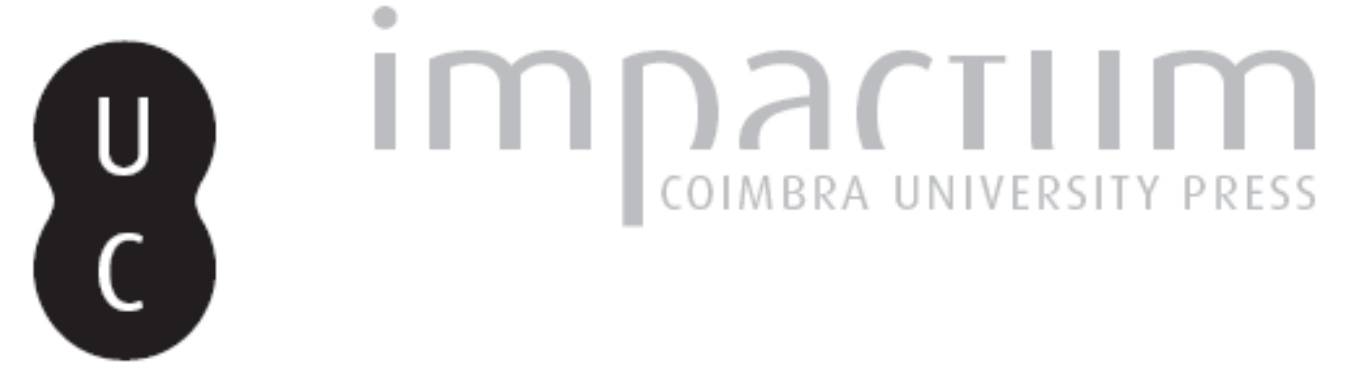

\title{
O sacrifício humano em prol da comunidade: a Andrômeda de Sófocles e o Erecteu de Eurípides
}

\author{
Autor(es): $\quad$ Ribeiro Jr., Wilso n Alves
}

Publicado por: Sociedade Brasileira de Estudos Clássicos

URL

persistente:

URI:http://hdl.handle.net/10316.2/35781

DOI:

DOI:http://dx.doi.org/10.14195/2176-6436_22-2_7

Accessed : $\quad$ 26-Apr-2023 11:08:44

A navegação consulta e descarregamento dos títulos inseridos nas Bibliotecas Digitais UC Digitalis, UC Pombalina e UC Impactum, pressupõem a aceitação plena e sem reservas dos Termos e Condições de Uso destas Bibliotecas Digitais, disponíveis em https://digitalis.uc.pt/pt-pt/termos.

Conforme exposto nos referidos Termos e Condições de Uso, o descarregamento de títulos de acesso restrito requer uma licença válida de autorização devendo o utilizador aceder ao(s) documento(s) a partir de um endereço de IP da instituição detentora da supramencionada licença.

Ao utilizador é apenas permitido o descarregamento para uso pessoal, pelo que o emprego do(s) título(s) descarregado(s) para outro fim, designadamente comercial, carece de autorização do respetivo autor ou editor da obra.

Na medida em que todas as obras da UC Digitalis se encontram protegidas pelo Código do Direito de Autor e Direitos Conexos e demais legislação aplicável, toda a cópia, parcial ou total, deste documento, nos casos em que é legalmente admitida, deverá conter ou fazer-se acompanhar por este aviso.

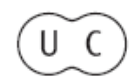




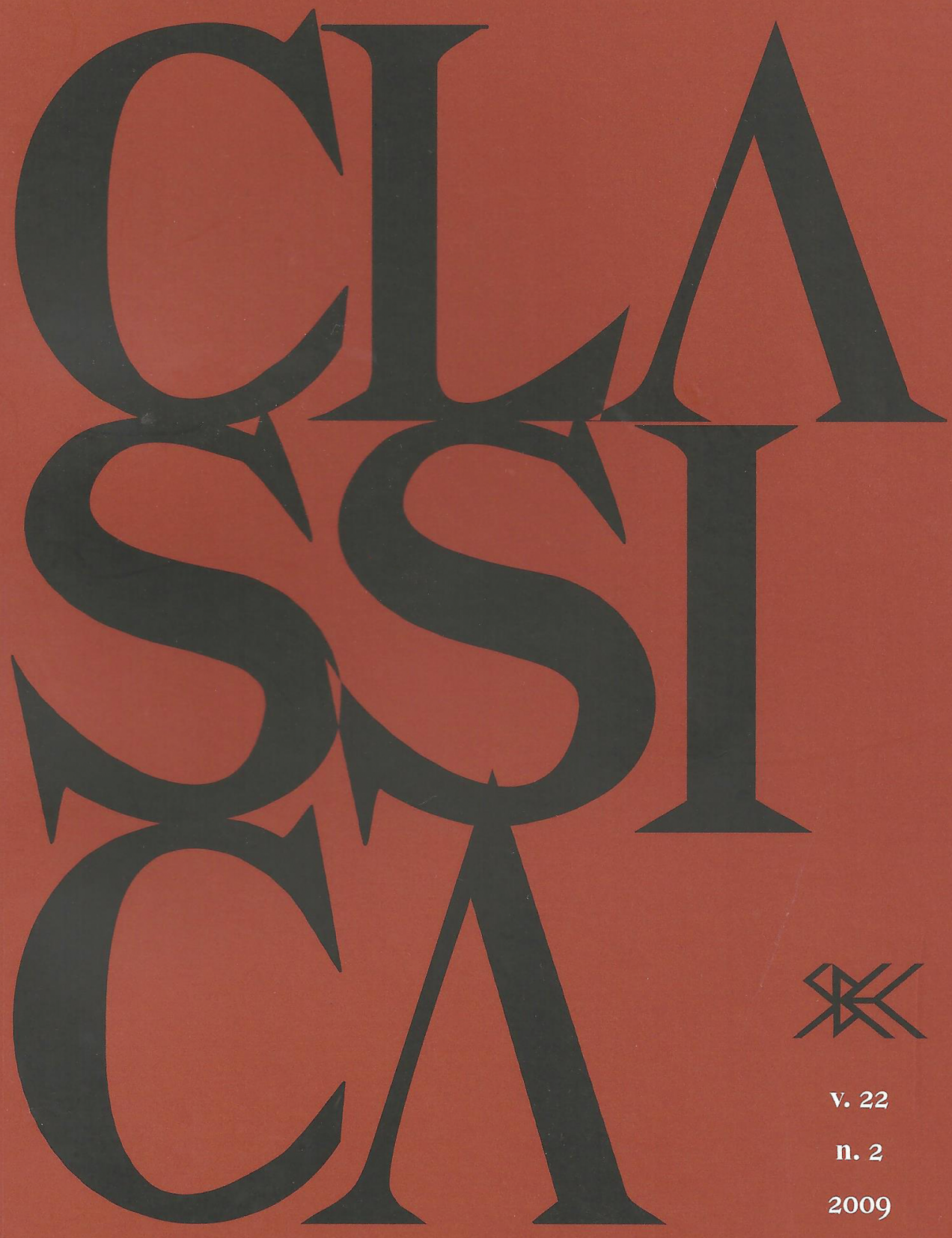




\title{
O sacrifício humano em prol da comunidade: a Andrômeda de Sófocles e o Erecteu de Eurípides
}

\author{
Wilson Alves Ribeiro JR. \\ Universidade de São Paulo \\ Brasil
}

RESUMO. Estudos relativamente detalhados sobre o tema do sacrifício humano nas tragédias clássicas integralmente conservadas tem sido publicados. Menos atenção, por outro lado, foi concedida às tragédias fragmentárias, dado o escasso material disponível. No presente estudo serão discutidos alguns fragmentos de duas tragédias incompletas, Andrômeda, de Sófocles, e Erecteu, de Eurípides, que descrevem sacrifícios humanos relacionados a uma das mais fortes motivações admitidas na Antiguidade: o sacrifício em prol da comunidade.

Palavras-chave. Teatro; tragédia grega; Sófocles; Eurípides; Erecteu; Andrômeda; sacrifício humano.

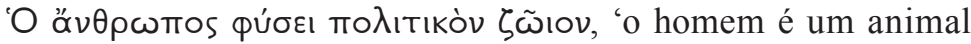
que vive, por natureza, em uma pólis', afirmou Aristóteles na Política (1253 a 2-3). ${ }^{1}$ Discussões filosóficas e históricas à parte, o filósofo sem dúvida se referia à tendência dos seres humanos de viver e conviver em grupos socialmente estruturados, regulados por normas, princípios e usos que, em última análise, mantêm o grupo próspero e coeso.

No contexto dos usos e costumes que beneficiam a comunidade, em detrimento do bem e dos interesses particulares de cada um, deve ser inserida a mítica prática do sacrifício humano, tema de diversas tragédias de Ésquilo, de Sófocles e de Eurípides. Os poetas trágicos adotaram esse tema de impacto, ao qual recorreram muitas vezes, devido ao enorme potencial trágico de sua representação teatral, como observou Sousa e Silva ${ }^{2}$, ou melhor, do apelo dramático da encenação dos eventos que conduziam

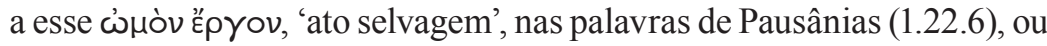

\section{Email: epwidos@gmail.com}

\footnotetext{
${ }^{1}$ Registre-se que a tradução 'o homem é, por natureza, um animal político', muito difundida entre os leigos, é decididamente incorreta. Aristóteles, aqui, referiu-se à mais importante instituição comunitária da Grécia Antiga, a pólis, e não ao que em nossos dias chamamos, com tonalidade um tanto pejorativa, de 'política'.

${ }^{2}$ Maria de Fátima Sousa e Silva, Sacrifício voluntário: teatralidade de um motivo euripidiano. Biblos 67, 15-41, 1991, p. 16.
} 


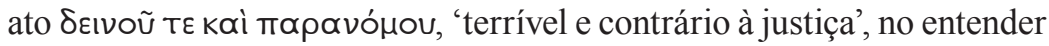
de Plutarco (Pel. 21.2).

Na realidade, nenhum dos relatos 'históricos' de sacrifícios humanos na Grécia Antiga (ver Clem. Al. Protr., 3.42; Porph. Abst., 2.53-6; Lact. Div. Inst. 1.21) foi confirmado, seja através da arqueologia, seja através de documentos não-literários ${ }^{3}$, o que não diminui o efeito trágico e o impacto dramático nas audiências da Antiguidade. De modo geral, os gregos do Período Clássico acreditavam que os sacrifícios humanos eram uma realidade histórica, situada porém no seu mais remoto passado (Lycurg. Orat. 98-101; Dem. Epit. 29; e Soph. Fr. 126 Radt, como se verá adiante).

$\mathrm{Na}$ obra de Eurípides, notadamente, encontramos o material mais extenso e mais importante para o estudo do sacrifício humano na tragédia grega. Nos dramas conservados, temos a cena do sacrifício de Polixena (Hec. 518-82) e a cena do sacrifício de Ifigênia (IA 1540-95), além de numerosas menções e passagens sobre esses e outros sacrifícios humanos em Heráclidas, Andrômaca, Troianas, Electra, Orestes, Ifigênia em Táuris e Bacantes. O enredo de Bacantes e Ifigênia em Áulis, duas das últimas tragédias de Eurípides, gira em torno de dois sacrifícios humanos iminentes (o de Penteu e o de Ifigênia, respectivamente). ${ }^{4}$ De Ésquilo, conservou-se uma boa descrição do sacrifício de Ifigênia na Oresteia (Ag. 228-49); nas tragédias de Sófocles que chegaram até nós, infelizmente, há apenas breves menções a mitos que envolvem o tema.

Vários estudos foram publicados, nos últimos anos, sobre os sacrifícios humanos em tragédias gregas completas; as tragédias fragmentárias, por outro lado, têm sido pouco estudadas. Nesta breve exposição, apresentarei os resultados preliminares de uma pesquisa sobre um dos tipos de sacrifício humano, o 'sacrifício em prol da comunidade', em duas tragédias incompletas que, sem sombra de dúvida, abordavam o tema: a

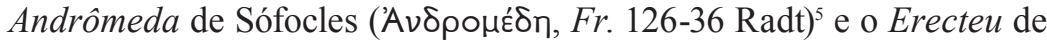

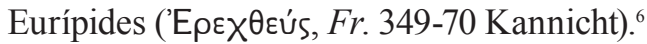

\footnotetext{
${ }^{3}$ Ver revisão e discussão dos relatos míticos e pseudo-históricos em Dennis D. Hughes, Human Sacrifice in Ancient Greece, London and New York, Routledge, 1991, notadamente sua conclusão às p. 13-48 e 73.

${ }^{4}$ Wilson A Ribeiro JR., 'Iphigenia aulidensis e Bacchae: festa, sacrifício e ironia trágica', in Fábio S. Lessa \& Regina M.C. Bustamante (org.), Memória \& Festa, Rio de Janeiro, Mauad, 2005, p. 629-36.

${ }^{5}$ Stefan Radt, Tragicorum Graecorum Fragmenta 4: Sophocles, Göttingen, Vandenhoeck \& Ruprecht, 1999, editio correctior et addendis aucta (= TrGF 4).

${ }^{6}$ Richard Kannicht, Tragicorum Graecorum Fragmenta 5.1: Euripides, Göttingen, Vandenhoeck \& Ruprecht, 2004 (= TrGF 5.1).
} 


\section{A Andrômeda sofocliana}

A Andrômeda de Sófocles foi representada, pela primeira vez, em data desconhecida. Embora Petersen ${ }^{7}$ ache que ela é anterior à Andrômeda de Eurípides, datada de 412 a.C., e talvez anterior à Alceste, de 438 a.C., não é possível ter certeza. Em uma cratera ática de fundo branco do Pintor da Fíale, datada de 440-435 a.C., atualmente conservada em Acragás, no Museo Archeologico Nazionale, há uma cena que corresponde, possivelmente, a uma representação da Andrômeda de Sófocles, mais exatamente ao momento em que Perseu encontra Andrômeda presa ao rochedo. Acima da

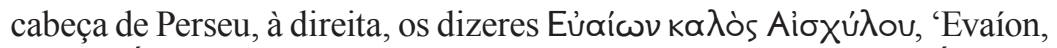
filho de Ésquilo, é belo', possivelmente indicam que esse filho de Ésquilo, que sabemos ter sido ator, pode ter representado o papel de Perseu. ${ }^{8}$

Dessa tragédia restam apenas dez curtos fragmentos e só um deles, o $F r$. ${ }^{* *} 133$, vem de um papiro (P.Oxy. 2453 fr. 49); todos os demais vêm de citações e testemunhos indiretos. Anteriormente, Casaubon, Brunck e Ribbeck consideraram a peça um drama satírico ${ }^{9}$ mas, desde os trabalhos de Welcker ${ }^{10}$, os estudiosos reconhecem o caráter trágico da peça. A reconstituição do argumento e da estrutura da tragédia baseia-se nos fragmentos, em alguns documentos iconográficos que chegaram até nós e nos dados do mito de Perseu e Andrômeda, conservados notadamente por Eratóstenes (Cat. 17), por Ovídio (Met. 4.663-5.249) e pelo Pseudo-Apolodoro (2.4.3).

$\mathrm{O}$ mito relata que, retornando à Grécia após a luta com Medusa, Perseu passou pela Etiópia e se deparou com Andrômeda presa a um rochedo, junto ao mar. Algum tempo antes, a esposa de Cefeu, o rei da Etiópia, gabou-se de ser mais bela do que as Nereidas, e por isso Posídon enviou um dilúvio e um terrível monstro marinho para assolar a região. Um oráculo predisse que se a princesa Andrômeda fosse oferecida ao monstro o problema cessaria. Pressionado pela população, o rei mandou prender a filha ao rochedo e deixou-a à mercê do monstro. Cefeu prometeu a mão da

\footnotetext{
${ }^{7}$ E. Petersen, Andromeda, The Journal of Hellenic Studies 24, 99-112, 1904, p. 108.

${ }^{8}$ Ver J.R. GreEn, On Seeing and Depicting the Theatre in Classical Athens, Greek, Roman and Bizantine Studies 32.1, 15-50, 1991; A.D. Trendall e T.B.L. WeBster, Illustrations of Greek Drama, London, Phaidon, 1971 e P. GhiRon-Bistagne, Recherches sur les acteurs dans la Grèce Antique, Paris, Belles Lettres, 1976.

${ }^{9}$ Isaac Casaubon, Animadversiones in Athenaei Dipnosophistas libri XV, Lyon, 1621; Richard F.P. BRUnCK, Sophoclis quae exstant omnia cum veterum grammaticorum scholiis, Strasbourg, Argentorati, 1786; Отто Rіввеск, Die römischen Tragödie im Zeitalter der Republik, Leipzig, 1870, p. 564.

${ }^{10}$ Friedrich G. Welcker, Die griechischen Tragödien mit Rücksicht auf den epischen Cyclus geordnet, Bonn, Weber, 1839-41.
} 
filha a Perseu, que se apaixonara pela jovem, e o herói matou o monstro, salvou sua prometida e ainda enfrentou e venceu um antigo pretendente de Andrômeda, Fineu, a quem petrificou com a cabeça de Medusa.

Petersen ${ }^{11}$ comparou a Andrômeda de Sófocles com a Alceste de Eurípides, com tragédias latinas de Ênio e Ácio e com várias cenas de vasos que podem representar, em certa extensão, cenas da peça $a^{12}$; sua reconstrução, embora altamente conjetural, dada a pobreza dos fragmentos, é ainda a mais aceita $^{13}$. A cena representava, provavelmente, o rochedo junto ao mar, e a tragédia começa com Cefeu e séquito prendendo Andrômeda ao rochedo. Logo depois, talvez, a jovem se lamenta, junto à mãe, Cassiopeia, ou sozinha. A seguir, quando Andrômeda está só (ou antes, durante seu apresamento), Perseu se aproxima e a encontra. Posteriormente, ele faz o acordo com Cefeu, vence Fineu (talvez um mensageiro apareça para noticiar) e vai-se embora com a princesa. É possível e provável que Sófocles tenha mostrado, em alguma parte, um ơ $\gamma \omega \dot{v}$ entre Perseu e Fineu, para contrapor a coragem e a superioridade moral do jovem grego à covardia do bárbaro, que não se arriscou para salvar a noiva, mas veio reclamá-la quando a viu salva (o tema da superioridade grega não é raro em Sófocles). Nada sabemos do coro; o protagonista deve ter representado Perseu ou Andrômeda.

O Fr. 126 é o único que podemos relacionar, com certeza, a uma das partes da tragédia que menciona o sacrifício (= Hsch. $\kappa 3859)$ :

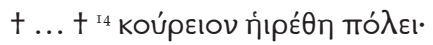

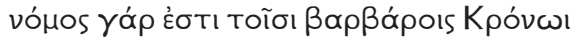

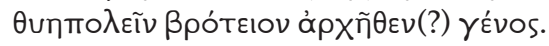

$\dagger \ldots \dagger$ ela foi designada vítima sacrificial pela pólis, pois há um costume entre esses Bárbaros de a Cronos sacrificar um ser humano, desde os tempos antigos.

Note-se que a exposição de Andrômeda ao monstro é efetivamente reconhecida como um sacrifício humano. O fragmento é declamado, provavelmente, por alguém que coloca Perseu a par dos acontecimentos.

\footnotetext{
${ }^{11}$ Ver Petersen, p. 108-12.

${ }^{12}$ Ver sumário da documentação iconográfica em Kyle M. Phillips JR., Perseus and Andromeda, American Journal of Archaeology 72.1, 1-23, 1968 e em GreEN, 1991.

${ }^{13}$ Ver também Chandler R. Post, The Dramatic Art of Sophocles as Revealed by the Fragments of the Lost Plays, Harvard Studies in Classical Philology 33, 1-63, 1922, p. 15-16.

${ }^{14}$ Diversas conjeturas foram propostas para essa passagem corrompida, e nenhuma delas é segura. Segundo J.M. Lucas de Dios (Sófocles - Fragmentos, Madrid, Gredos, 1983, p. 70, n. 165), nenhuma conjetura altera o sentido geral da passagem, uma alusão à Andrômeda e seu sacrifício em benefício da comunidade.
} 


\section{O Erecteu de Eurípides}

Do Erecteu temos 26 fragmentos, três deles bem extensos; é uma tragédia bem mais conhecida do que a Andrômeda sofocliana e dela tratarei com mais brevidade, pois os fragmentos sobreviventes permitem uma boa reconstrução da peça, já razoavelmente conhecida pelos especialistas. ${ }^{15}$

O mito é relativamente simples: Erecteu, um dos antigos reis de Atenas, aconselhado pelo Oráculo de Delfos, sacrificou uma de suas filhas para assegurar a vitória durante uma guerra com Elêusis, pólis da Ática que se associara a Eumolpo, rei da Trácia, para atacar Atenas (ver Lycurg. Orat. 98-101, Phanod. fr. F4, Paus. 3.15.4 e Ps.-Plut.Mor. 310d, entre outras fontes).

A tragédia foi representada com certeza entre 420 e 410 a.C. e o coro era constituído por velhos atenienses. A cena representa o palácio de Erecteu e o prólogo é apresentado por Posídon, que possivelmente antecipa os próximos acontecimentos, como faz Afrodite no Hipólito. Depois, entra Erecteu, recém-chegado de Delfos, onde o oráculo prescreveu o sacrifício de uma de suas filhas para salvar Atenas (os atenienses estão em desvantagem diante dos eleusinos e dos trácios). Inicialmente, Erecteu resiste à ideia, mas sua esposa Praxítea decide renunciar à filha para salvar sua cidade; o sacrífico é, talvez, descrito por um mensageiro. Antes da batalha, Erecteu prevê a própria morte e dá conselhos ao filho; mais tarde, um mensageiro traz a notícia da vitória ateniense, da morte de Eumolpo, da morte do rei e também, possivelmente, do suicídio das outras filhas de Erecteu, solidárias com a morte da irmã (cf. Apollod. 3.15.4 e Hyg. Fab. 46). Após os lamentos de praxe, um terremoto provocado por Posídon abala o palácio, mas Atena, ex machina, intervém e apazigua os adversários e o tio. O protagonista pode ter representado tanto o papel de Erecteu, como o de Praxítea.

Interessam ao nosso tema, especificamente, os Fr. 360 e 360a, conservados respectivamente por Licurgo, na oração Contra Leocares (Orat. 100), e por Plutarco (Mor. 809d). Aqui, apresento a tradução dos trechos relevantes do $F r$. 360 e o único verso do $F r$. 360a. Eis o Fr. 360.4-55, declamado por Praxítea:

\footnotetext{
${ }^{15}$ Ver discussão dos fragmentos e reconstituição conjetural de MARTIN J. CROPP no capítulo 'Erectheus', in Christopher Collard, Martin J. Cropp \& Kevin H. Lee, Euripides Selected Fragmentary Plays 1, Warminster, Aris \& Phillips, 1997, p. 148-94. Quase todos os dados que apresento a seguir se baseiam nesse estudo.
} 


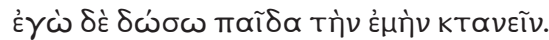

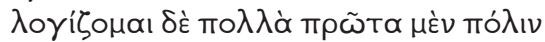

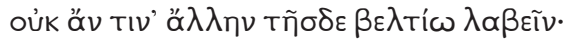

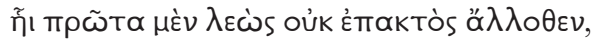

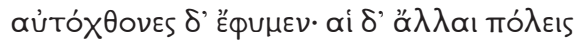

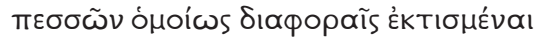

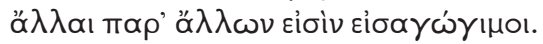

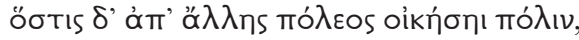

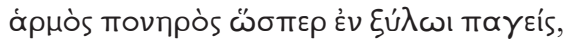

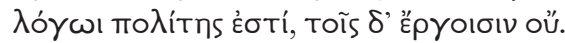

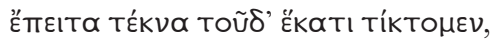

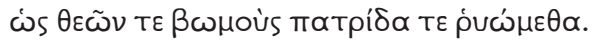

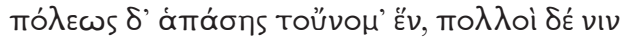

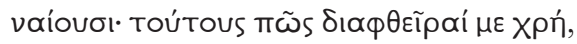

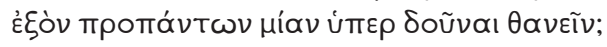

E⿱ $\delta^{\prime}$ ก๊

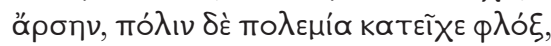

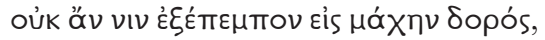

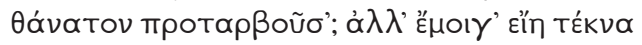

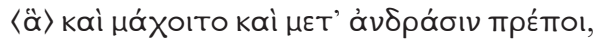

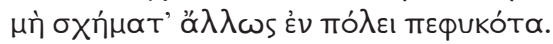

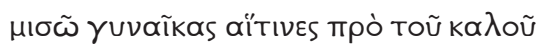

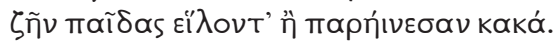

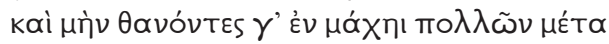

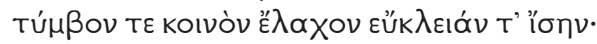

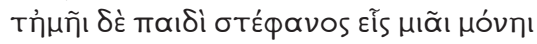

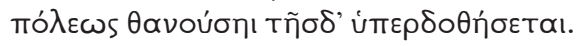

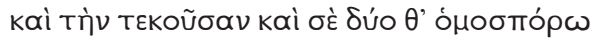

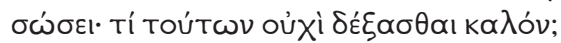

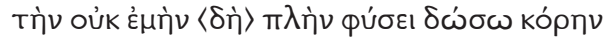

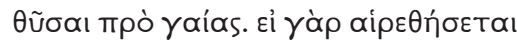

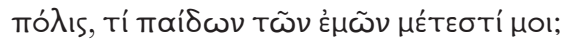

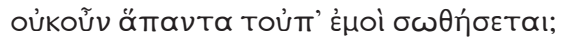

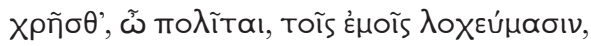

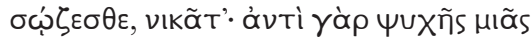

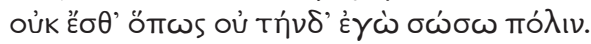

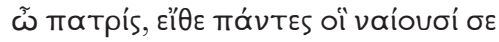

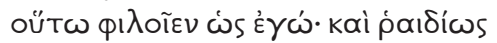

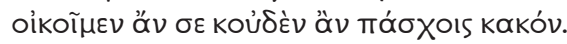


Eu darei, então, minha filha para matarem.

Levo em conta muitas coisas. Primeiro, não há outra pólis melhor do que esta para encontrar. Para começar, o povo não veio de outro lugar, somos autóctones. As outras póleis, povoadas como peças variadas de um jogo, são importadas, formadas por povos diferentes. Quem se estabele em uma pólis, vindo de outra, é como uma cavilha mal colocada em um pedaço de madeira, um cidadão de nome, mas não de fato.

Segundo, a razão para darmos à luz filhos é protegermos os altares dos deuses e a pátria. A pólis toda tem um único nome, mas são muitos os habitantes; como é possível, a mim, destruí-los se posso enviar uma só para morrer por todos?

Se em nossa casa houvesse uma prole masculina, ao invés de feminina, e a chama da guerra tomasse a pólis, não os mandaria eu para a batalha, por medo de sua morte? Não, deem-me filhos que lutem e pareçam homens, não figuras criadas na pólis para outras coisas.

Detesto as mulheres que, em detrimento da virtude, escolhem a vida dos filhos, ou recomendam coisas más. ${ }^{16}$

Os (filhos) que morrem em batalha recebem uma tumba em comum e têm a mesma glória de muitos; minha filha terá uma coroa única, só para ela, quando for enviada para a morte em prol desta pólis, e salvar quem a pôs no mundo, tu e as duas irmãs; qual dessas coisas não é uma bela (recompensa)? A donzela, que não é minha exceto pela natureza, darei para ser sacrificada em prol da terra. Se for tomada a pólis, que parte dos meus filhos me caberá?

Não deve, pois, ser salvo o todo, se isso está ao meu alcance?

Usai, cidadãos, os que nasceram de mim, salvai-vos, vencei! Em lugar de uma só alma, não há meio de eu não salvar esta pólis. Ó pátria, oxalá todos os teus habitantes te amem assim, como eu; sem dificuldades moraríamos em ti, e nunca sofrerias nenhum mal.

${ }^{16} \mathrm{Ou}$ 'recomendam a covardia'? Interpretação de Cropp (CROPP, 1997, ad loc.). 


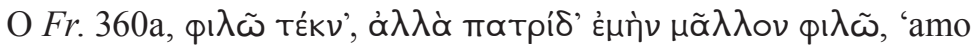
minha filha, mas amo mais a minha pátria,' complementa o discurso de Praxítea e introduz um dos principais temas de Eurípedes para o Erecteu, o amor à pátria e o bem da pólis a todo custo. Para o poeta, nenhuma renúncia é pequena demais - e isso transparece com pujança de detalhes no Fr. 360, do qual o Fr. 360a nada mais é do que uma epítome. Isso se deve, sem dúvida, às adversidades de Atenas durante a Guerra do Peloponeso.

Há muitos outros pontos interessantes na tragédia, como o da equiparação entre a morte sacrificial da mulher com a morte do homem em batalha e a esperança de retribuição apropriada - pois um grego sempre espera algum tipo de retribuição -, mais exatamente o reconhecimento, as homenagens e as honras prestadas após a morte. ${ }^{17}$

\section{Tudo pela comunidade}

As duas tragédias que acabei de discutir são exemplos típicos de extremados 'sacrifício em prol da comunidade' e o Fr. 360 do Erecteu praticamente codifica a lei que rege a fria lógica desse procedimento. No mito $^{18}$ e na tragédia ática o sacrifício humano é, quase sempre, prescrito pelo oráculo de uma divindade ou por um adivinho (Andrômeda: oráculo de Amon; Erecteu: oráculo de Delfos). As vítimas são, com grande frequência, jovens, puras, voluntárias e do sexo feminino. O sacrifício é uma solução para um grave problema que põe em perigo a cidade ou a família da vítima - uma guerra perigosa, uma praga, ou simplesmente a fome (Andrômeda: dilúvio e monstro marinho; Erecteu: guerra).

Há quase sempre, portanto, uma situação de desordem que procura ser reordenada pelo sacrifício. Uma divindade, em geral Ártemis, Dioniso ou Zeus, está diretamente envolvida e às vezes atenua o ritual, substituindo a vítima humana por um animal ou por algum outro rito mais aceitável (a Andrômeda é um tanto atípica, nesse aspecto). Hughes ${ }^{19}$, que sistematizou grande parte dessas observações, notou ademais que a maioria dos relatos segue um padrão sequencial: transgressão, praga, oráculo, instituição do sacrifício humano.

Nos mitos, notadamente nos de fundo etiológico, muitas vezes o sacrifício é seguido pela abolição dessa prática, desse ato selvagem, terrível

\footnotetext{
${ }^{17}$ Ver Wilson A. Ribeiro JR., 'Iphigenia Aulidensis' de Eurípides, Dissertação de Mestrado, Universidade de São Paulo, 2006, p. 100-2.

${ }^{18}$ Ver os principais mitos gregos que envolvem sacrifícios humanos em RiBEIRO JR. (2006, p. 299).

${ }_{19}$ Ver Hugues, 1991.
} 
e contrário à justiça, como bem observaram Pausânias e Plutarco. Nas tragédias aqui apresentadas, por outro lado, o mito serve de fundo a formas individuais e extremadas de patriotismo, tudo em nome do bem comum.

TITLE. Human sacrifice on behalf of the community: the Andromeda of Sophocles and the Erechtheus of Euripides

AвSTRACT. A few detailed studies on the subject of human sacrifice in fully preserved classical tragedies have been published. Less attention, however, was directed so far to fragmentary tragedies, probably because of the limitations of available material. This paper discuss some incomplete fragments of two tragedies, the Andromeda of Sophocles and the Erechtheus of Euripides, that emphasize human sacrifices related to one of the strongest motivations discussed in Antiquity: the sacrifice on behalf for the community.

KeYwords. Theater; greek tragedy; Sophocles; Euripides; Erechtheus; Andromeda; human sacrifice. 